\title{
Compaction/Liquefaction Properties of Some Model Sands
}

\author{
Andrzej Sawicki, Jacek Mierczyński, Justyna Sławińska \\ Institute of Hydro-Engineering, Polish Academy of Sciences, ul. Kościerska 7, 80-328 Gdańsk, Poland, \\ e-mails: as@ibwpan.gda.pl,mier@ibwpan.gda.pl, stynaju@ibwpan.gda.pl
}

(Received October 06, 2015; revised October 30, 2015)

\begin{abstract}
The compaction/liquefaction characteristics of two model sands are determined experimentally. One sand (Istanbul) is used in shaking table investigations, and the other (Dundee) in geotechnical centrifuge experiments. Both types of these highly sophisticated experiments are planned to be applied to test theories of seabed liquefaction. The first step of these experiments is to determine the parameters of model soils, which is the main goal of this paper.
\end{abstract}

Key words: Soil compaction, liquefaction, parameters, experimental data

\section{Introduction}

The problem of soil liquefaction has attracted the attention of soil mechanics researchers for more than half a century. This phenomenon is not discussed in the classical literature on the mechanics of materials, as it occurs only in saturated soils. Recall that the classical literature is devoted mainly to such properties of solids as elasticity, plasticity, strength, and viscosity, because they determine the strength and serviceability of typical structures. A variety of classical models of materials have been adopted in soil mechanics in order to describe their behavior, but not always with success. Typical examples are hundreds of elasto-plastic models of soils, which are still not completely satisfactory, see Saada and Bianchini (1989). Since that time, not much has changed. Soil liquefaction is a unique phenomenon, which needs a different treatment from that applied in the classical mechanics of materials.

Research in the field of soil liquefaction is twofold. The most common is its empirical, or geotechnical, branch, which seeks to find simple methods for liquefaction assessment, as for example in Rahman et al (2015), Papathanassiou et al (2015). The other, rather rare, branch is theoretical, or geomechanical, where models of liquefaction are developed. There is no symmetry between these two approaches, as the geotechnical one prevails due to its apparent simplicity. Therefore, design guidelines contain only general suggestions on how to deal with liquefaction problems, without details or mechanical models, see PIANC (2001). 
The basic question asked by geotechnical engineers is which soil is liquefiable, and which is not. It is commonly accepted that saturated sands are liquefiable, as well as some mixtures of sand and silt. Differences of opinion persist, however, as to the liquefaction properties of clay and gravel. Note that the strength of classical structures depends on their geometry, mechanical properties, and loads applied. The structural engineer does not ask whether metals can be destroyed or not, because it is obvious that they can, but rather he analyzes conditions leading to their failure. The same methodology can be applied to soil liquefaction.

It can be done in two stages. The first stage consists of the elementary investigations of soil properties in the laboratory. The second is related to a specific initial/boundary value problem. Recall that the same soil may liquefy under certain conditions, or may not when these external conditions, such as the intensity of applied loads, are different. This paper focuses on the first stage, i.e. laboratory investigations of the liquefaction properties of two model sands. The first sand, designated as "Istanbul," is used in shaking table investigations at the Istanbul Technical University (Turkey). The second, designated as "Dundee", is used in geotechnical centrifuge investigations at the University of Dundee (Scotland). Experiments performed at these universities are related to seabed mechanics, in connection with multi-use offshore platforms (the EU research program MERMAID).

The liquefaction properties of the two soils were determined within the framework of theoretical models of liquefaction developed at the Institute of Hydro-Engineering. These models will be applied in the interpretation of the above-mentioned experiments.

\section{Geotechnical Models}

The problem of modeling in soil mechanics requires a separate treatment, probably in the form of an extensive book. Here we will limit ourselves to the simplest and best known model, that is the Coulomb-Mohr failure criterion, describing the failure of soils. This criterion contains two parameters, namely the angle of internal friction $\varphi$ and cohesion $c$, which can be determined for a given soil in any geotechnical laboratory. Having determined these parameters, one can analyze various particular problems and assess whether a given soil mass or geotechnical structure will remain stable under loads applied. Another simple model, widely applied in mechanics of materials, is Hooke's law, describing the elastic properties of solids. Hooke's model contains two basic parameters, namely the Young modulus $E$ and Poisson's ratio $v$, which are also widely known.

Each model has some parameters that should be determined experimentally. The above models, i.e. the Coulomb-Mohr failure criterion and Hooke's law, are commonly accepted, so their parameters are widely understood. Problems appear when non-classical models are introduced, containing some parameters, the meaning of which is generally unknown to the geotechnical community. In order to understand 
them, separate extensive studies of a particular model are necessary, which is usually a difficult and time-consuming task. That is why new models of soils have little chance of being accepted.

In spite of the above difficulties, we shall analyze the liquefaction properties of selected soils within the framework of theoretical models developed at the Institute of Hydro-Engineering. We believe that such an approach is more reliable than empirical methods adopted in geotechnical engineering. Some ideas presented in this paper have already been published, see Sawicki and Świdziński (2006) or Sawicki et al (2014a). Also note that a variety of other approaches have also been suggested, see Ishihara (1996), Lade and Yamamuro (1999), Jefferies and Been (2006).

\section{Standard Physical Properties of Investigated Soils}

Table 1 shows the standard physical characteristics of the two sands under investigation. The angle of internal friction was determined from tests performed in a triaxial apparatus for the "geotechnical" stress path (vertical effective stress increases, the cell pressure is kept constant). Fig. 1 shows the grain size distribution curves of these sands, plotted together with the Tsuchida curves. It follows from the location of these curves that both sands are liquefiable according to Tsuchida's (1970) concept (after Ishihara et al 1980). Note that these curves are almost identical. The differences between the extreme void ratios probably stem from different shapes of grains, see Figs. 2 and 3.

Table 1. Basic physical parameters of investigated soils

\begin{tabular}{|l|c|c|}
\hline \multicolumn{1}{|c|}{ Soil parameters } & Dundee sand & Istanbul sand \\
\hline Specific gravity & 2.647 & 2.653 \\
\hline Median size of grains $D_{50}(\mathrm{~mm})$ & 0.137 & 0.128 \\
\hline Maximum void ratio $e_{\max }$ & 0.83 & 1.092 \\
\hline Minimum void ratio $e_{\min }$ & 0.542 & 0.699 \\
\hline Angle of internal friction $\varphi\left({ }^{\circ}\right)$ & $35.5^{\circ}$ & $34.4^{\circ}$ \\
& for $I_{D}=0.69$ & for $I_{D}=0$ \\
\hline Hydraulic permeability $(\mathrm{m} / \mathrm{s})$ & $0.63 \times 10^{-4}$ & $0.79 \times 10^{-4}$ \\
\hline
\end{tabular}

\section{The Steady-State Line}

The steady state (SS) is defined as an unconfined plastic flow of granular soil under constant stresses and volume. The behavior of soil preceding the SS depends on its initial state, which may be either contractive or dilative. The initial state of soil is defined by its initial void ratio $e_{0}$ and the initial value of the mean effective stress $p_{0}^{\prime}$, represented as a point in space, see Fig. 4.

The point A corresponds to an initially contractive state. It means that a dry soil, or a saturated soil with free drainage allowed, compacts during pure shearing $\left(p^{\prime}=p_{0}^{\prime}=\right.$ const $)$ along the path $\mathrm{AB}$. Under undrained conditions, the phenomenon 


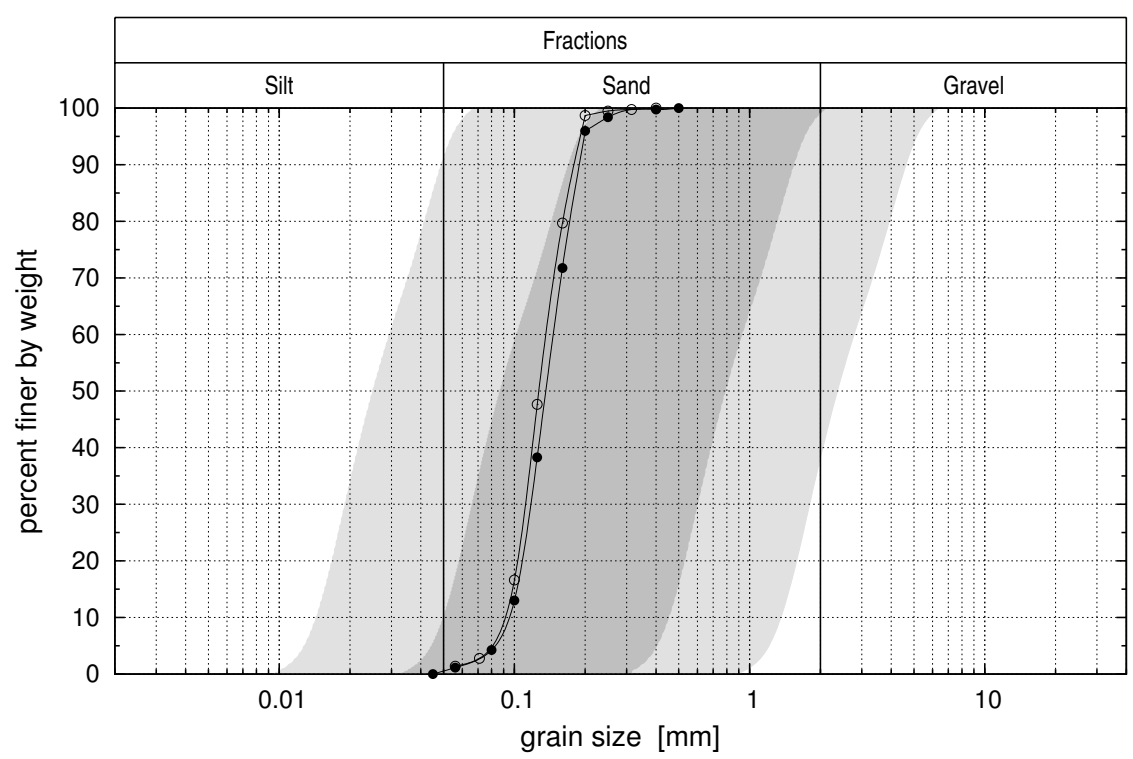

Fig. 1. Grain size distribution curves for the Dundee and Istanbul sands: $\bullet-$ Dundee sand, ○ - Istanbul sand. Tsuchida's curves are borders between respective zones:

liquefiable - dark grey, less liquefiable - light grey

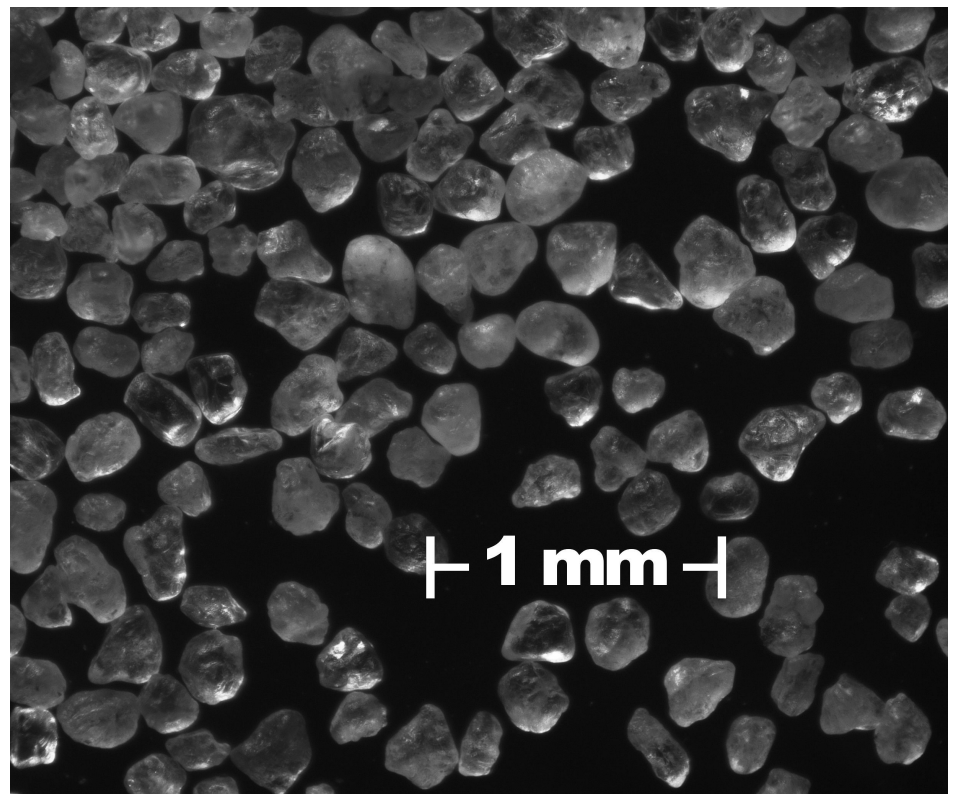

Fig. 2. Grains of the Dundee sand (under a microscope) 


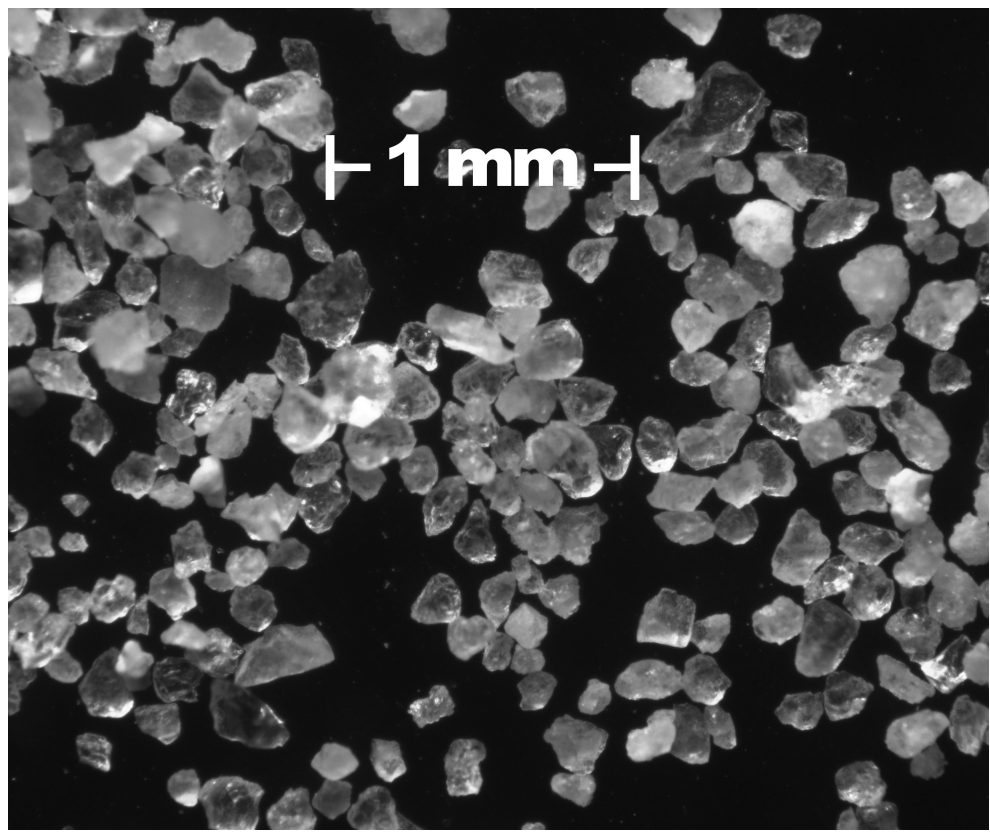

Fig. 3. Grains of the Istanbul sand (under a microscope)

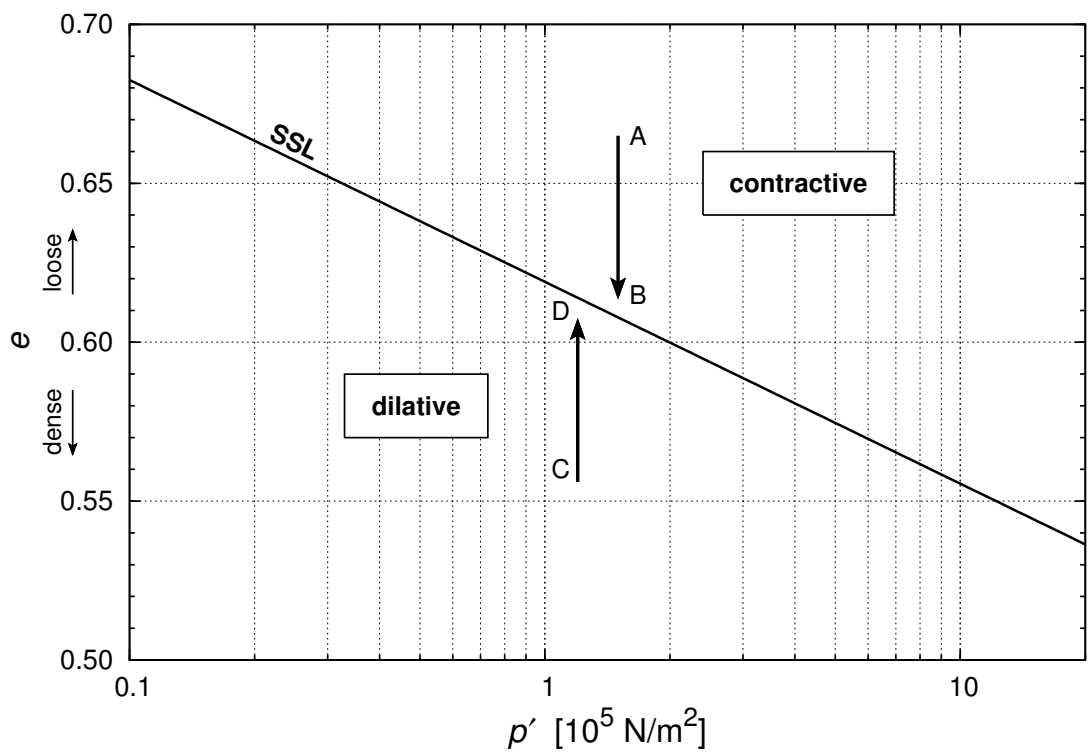

Fig. 4. The steady-state line (SSL) divides regions of initially contractive and dilative states 
of static liquefaction takes place. The point $\mathrm{C}$ corresponds to an initially dilative state. In this case, during pure shearing, a dry soil compacts first and then dilates. The behavior of an initially dilative soil, sheared under undrained conditions, differs from that of an initially contractive soil, as shown in Fig. 5. It is important to note that liquefaction does not take place in initially dilative soils, but only in contractive ones.

The SSL is usually determined from a series of experiments performed in a triaxial apparatus under both drained and undrained conditions. There are two important objects in the space of effective stresses, as shown in Fig. 5, drawn for axisymmetrical conditions, such as those in the triaxial apparatus. The co-ordinates of the effective stress space are $p^{\prime}=$ mean effective stress and $q=$ deviatoric stress, which are defined as follows:

$$
\begin{gathered}
p^{\prime}=\frac{\sigma_{z}^{\prime}+2 \sigma_{x}^{\prime}}{3}, \\
q=\sigma_{z}^{\prime}-\sigma_{x}^{\prime},
\end{gathered}
$$

where $\sigma_{x}^{\prime}=$ horizontal effective stress, $\sigma_{z}^{\prime}=$ vertical effective stress.

The first important object is the Coulomb-Mohr failure line, corresponding to the SS. The other object is the instability line (IL), which corresponds to the maximum shear stress that can be supported by undrained soil during shearing. The IL also corresponds to the maximum initial compaction of an initially dilative drained soil during shearing, preceding stronger dilation (see Sawicki et al 2014b). Fig. 6 shows the steady-state lines for the Dundee and Istanbul sands.

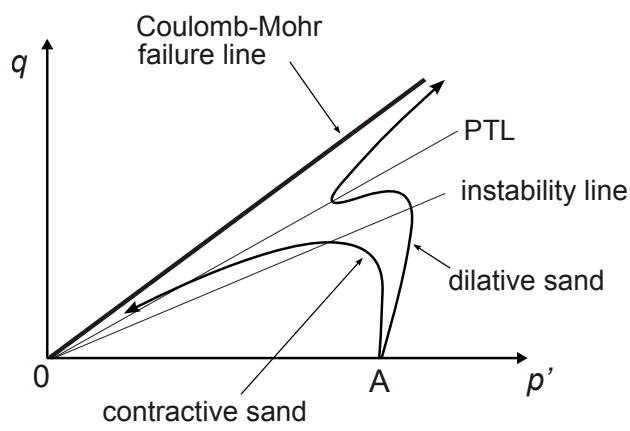

Fig. 5. Effective stress paths followed during undrained shearing of initially contractive and dilative soils. The phase transformation line (PTL) is characteristic for initially dilative sands 


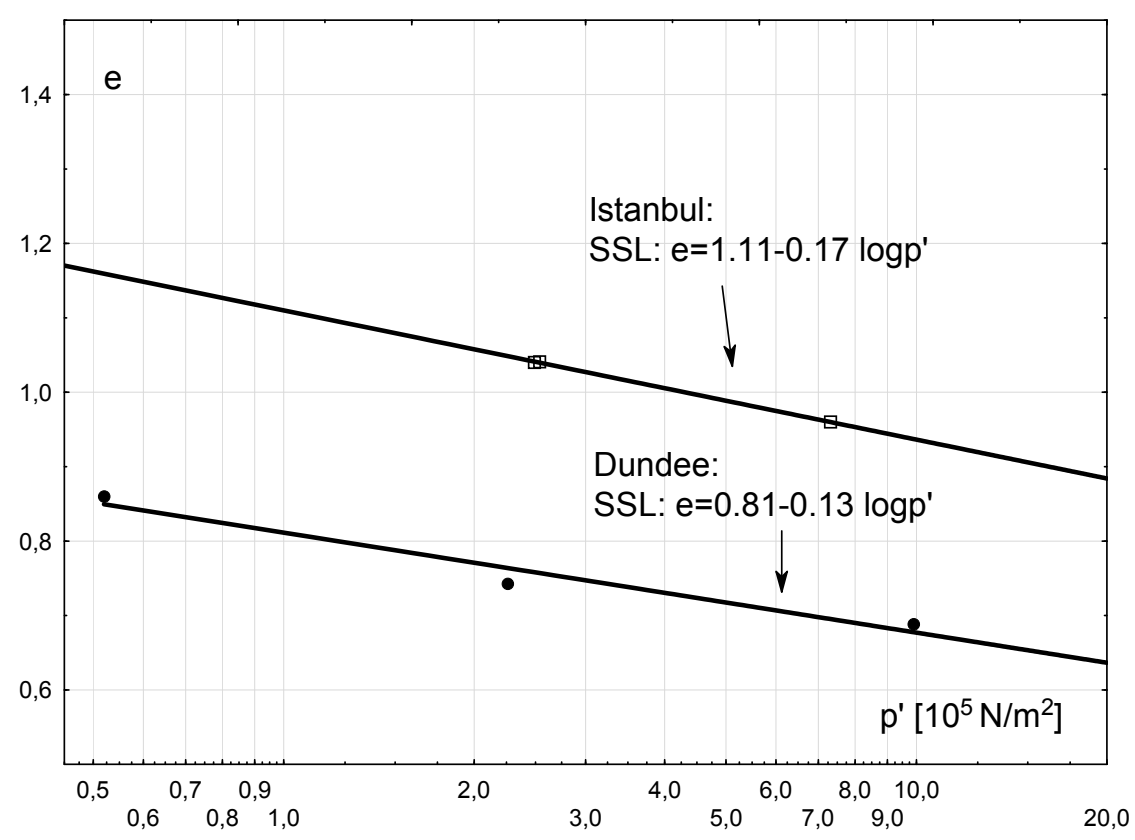

Fig. 6. Steady-state lines for the Dundee and Istanbul sands

\section{The Common Compaction Curve}

The common compaction curve in its present form was originally proposed by Sawicki (1987). It is a non-standard characteristic of granular soils, which describes their compaction and liquefaction properties in the case of cyclic loadings. This idea has been described in many publications, so there is no need to repeat from those texts, see Sawicki and Świdziński (2006), Sawicki et al (2014a). The basic tests are performed in the cyclic simple shear apparatus - in this case, specially constructed for the purpose at the Institute of Hydro-Engineering. Soil samples are subjected to cyclic loading at a given amplitude of the shear strain. The compaction of sand is recorded as a function of loading cycles. Then, the results are plotted in the $z$, $\Phi$ space, where:

$$
\begin{gathered}
z=\frac{\gamma_{0}^{2} N}{4}, \\
\Phi=\frac{1-n_{0}}{n_{0}} \varepsilon_{v} .
\end{gathered}
$$

The following notation is used: $\gamma_{0}=$ the amplitude of cyclic strain; $N=$ the number of loading cycles treated as a continuous variable; $n_{0}=$ initial porosity; $\varepsilon_{v}=$ volumetric strain. 
At least for a small number of loading cycles (up to about 100), these curves can be approximated by a single curve, designated as the common compaction curve, defined by the following equation:

$$
\Phi=C_{1} \ln \left(1+C_{2} z\right)
$$

where $C_{1}$ and $C_{2}$ are model constants.

Figs. 7 and 8 show the common compaction curves for the Dundee and Istanbul sands. Note that the experiments were performed for three values of the vertical stress.

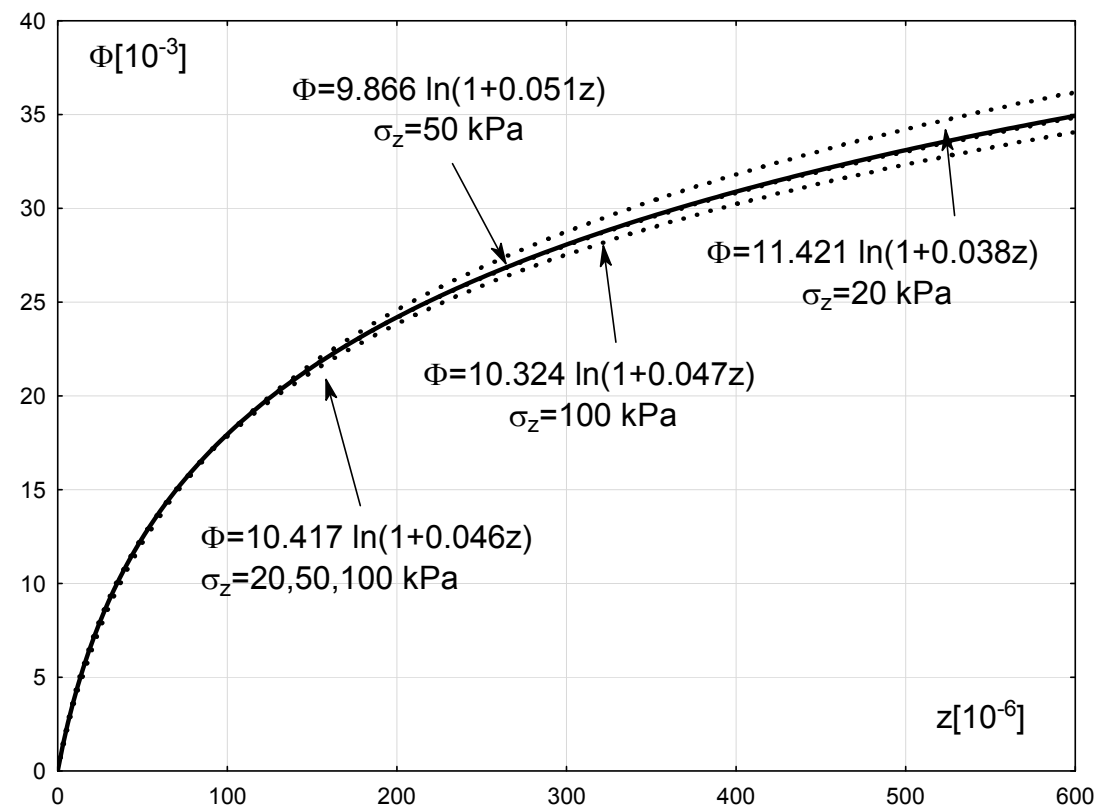

Fig. 7. The common compaction curve for the Dundee sand

The corresponding coefficients do not vary too much, as shown in Table 2, which supports the soil mechanics supposition that compaction does not depend on the mean effective stress. Fig. 9 shows the average compaction curves for both model sands. It follows that the Dundee sand is much more compactible than the Istanbul sand.

Recall that there is a direct link between the compaction properties of sand and its liquefiability, i.e. stronger compactibility is associated with greater liquefaction potential, see Sawicki (1987). It follows from Fig. 9 that the Dundee sand is more liquefiable than the other.

\section{Shear Modulus}

In soil mechanics, the notion of shear modulus $G$ has been adopted from the theory of elasticity, where it is a coefficient of proportionality between the stress deviator $\sigma^{\text {dev }}$ 


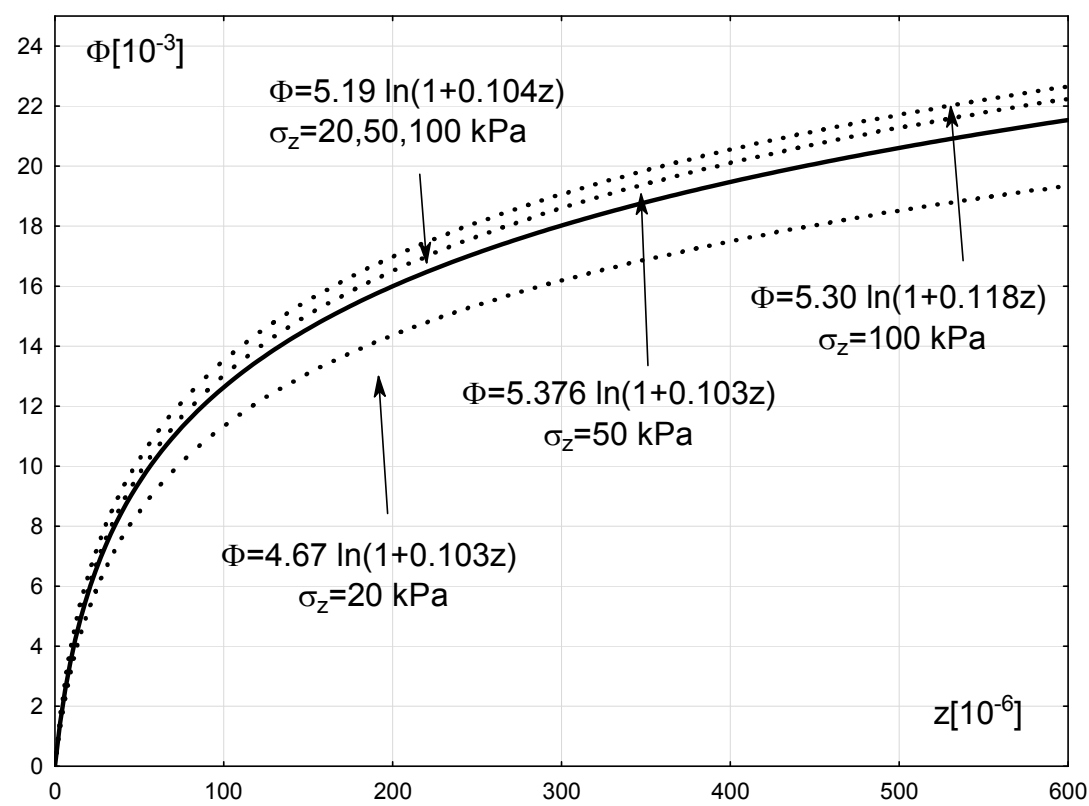

Fig. 8. The common compaction curve for the Istanbul sand

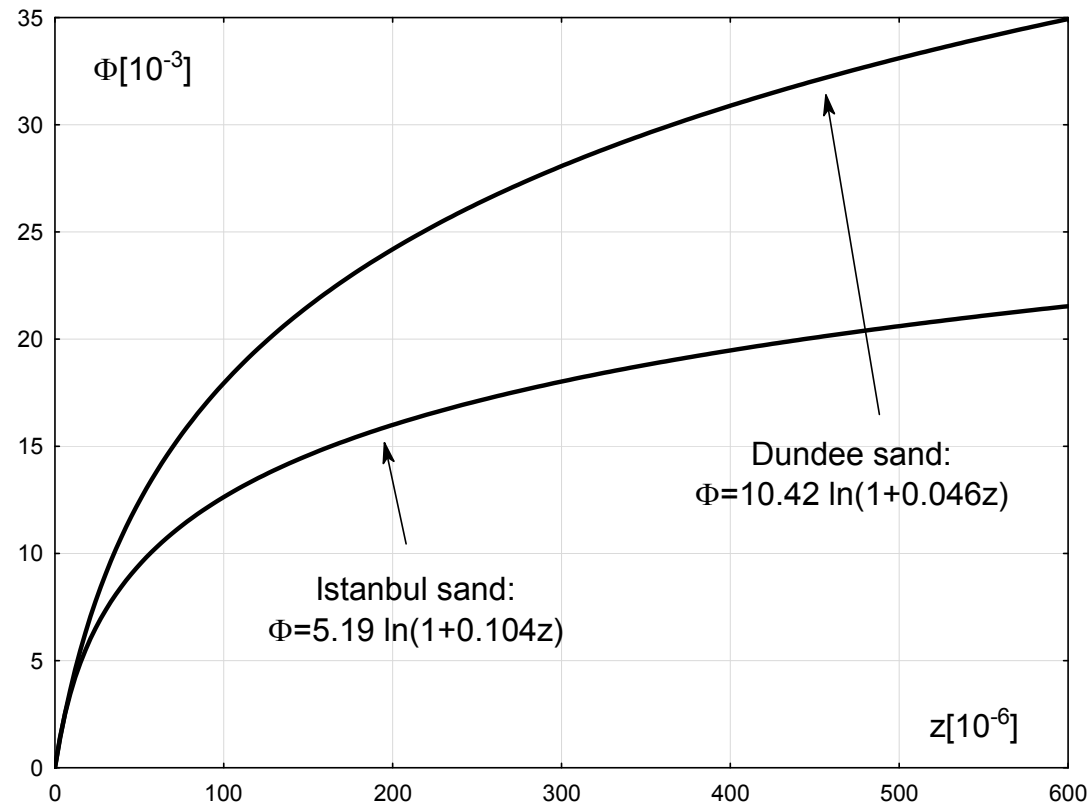

Fig. 9. Comparison of the average compaction curves for the two model sands 
Table 2. Compaction coefficients of the model sands

\begin{tabular}{|c|c|c|c|c|}
\hline \multirow{2}{*}{$\sigma_{z}$} & \multicolumn{2}{|c|}{ Dundee } & \multicolumn{2}{c|}{ Istanbul } \\
\cline { 2 - 5 }$(\mathrm{kPa})$ & $C_{1}$ & $C_{2}$ & $C_{1}$ & $C_{2}$ \\
\hline 20 & 11.421 & 0.038 & 4.67 & 0.103 \\
\hline 50 & 9.866 & 0.051 & 5.376 & 0.103 \\
\hline 100 & 10.324 & 0.047 & 5.30 & 0.118 \\
\hline average & 10.417 & 0.046 & 5.19 & 0.104 \\
\hline
\end{tabular}

and the strain deviator $\varepsilon^{\text {dev }}$ :

$$
\sigma^{d e v}=2 G \varepsilon^{d e v}
$$

For soils, it depends on the initial density, the mean effective stress $p$, and some other factors, such as the shear strain amplitude etc. There are different methods of determining $G$. We shall present the results obtained from two types of experiments performed in the triaxial apparatus.

\subsection{Propagation of the Acoustic Wave}

It is assumed that for small stresses elastic waves propagate in soil. The velocity of their propagation $V_{s}$ is given by the following formula:

$$
V_{s}=\sqrt{G / \rho},
$$

where $\rho$ is soil density.

Fig. 10 and 11 show the curves $G=G\left(p^{\prime}\right)$ for the two model sands.

The average density indices for the results shown in Figs. 10 and 11 are $I_{D}=0.4$ for the Dundee sand and $I_{D}=0.59$ for the Istanbul sand.

\subsection{Static triaxial investigations}

Fig. 12 and Fig. 13 show similar relationships obtained from static triaxial tests.

Note that the results obtained by the two methods differ, but these differences have been caused by different experimental conditions.

\section{Conclusion}

The main result of this paper is a set of compaction/liquefaction characteristics determined experimentally for two model sands. One of them (Istanbul) is used in experimental investigations on the shaking table, and the other (Dundee) in experiments performed in the geotechnical centrifuge. Both types of experiments are quite rare in geotechnical engineering because of high costs and extensive knowledge of non-classical methods required. Such experiments may lead to a better understanding of mechanics of liquefaction. As a precondition for testing various models of liquefaction, it is necessary to determine the parameters appearing in these models. The present paper satisfies this precondition. 


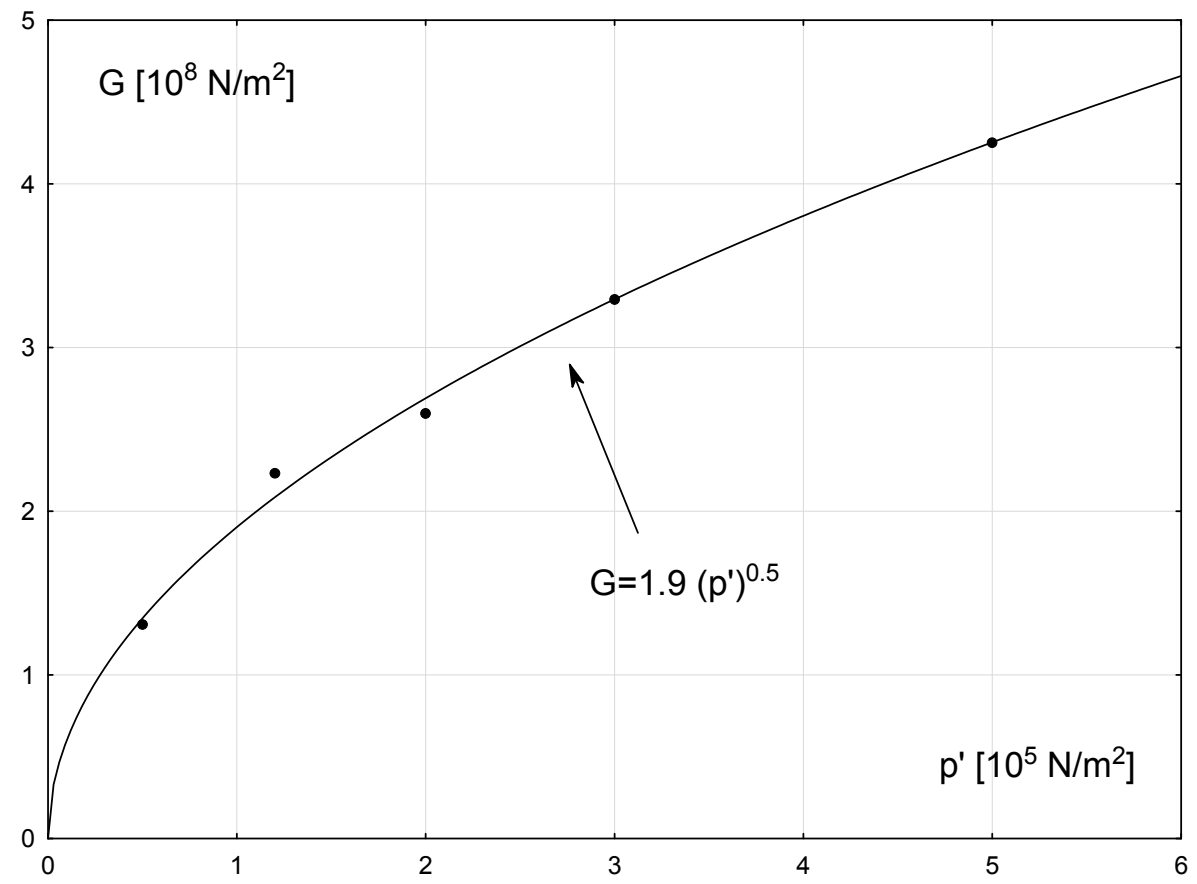

Fig. 10. Relation $G=G\left(p^{\prime}\right)$ for the Dundee sand, obtained from wave propagation tests

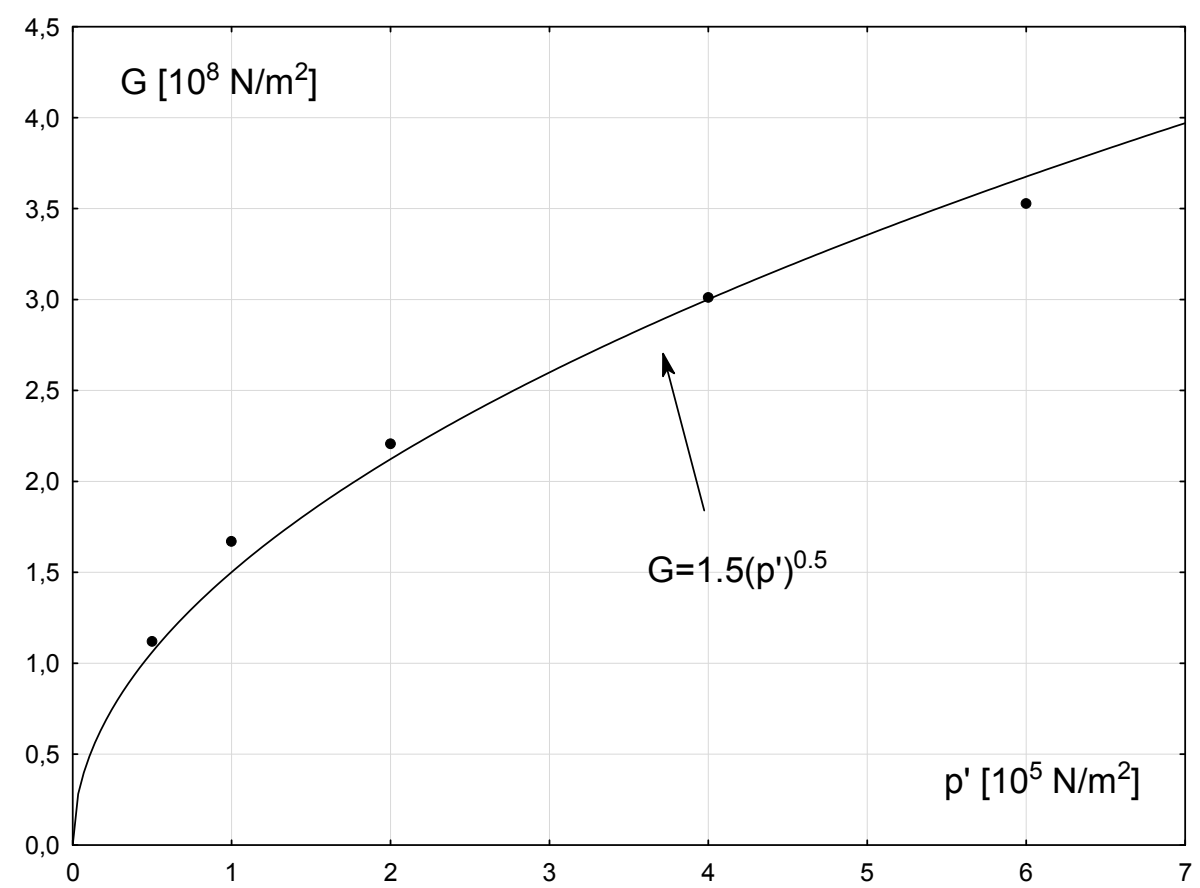

Fig. 11. Relation $G=G\left(p^{\prime}\right)$ for the Istanbul sand, obtained from wave propagation tests 


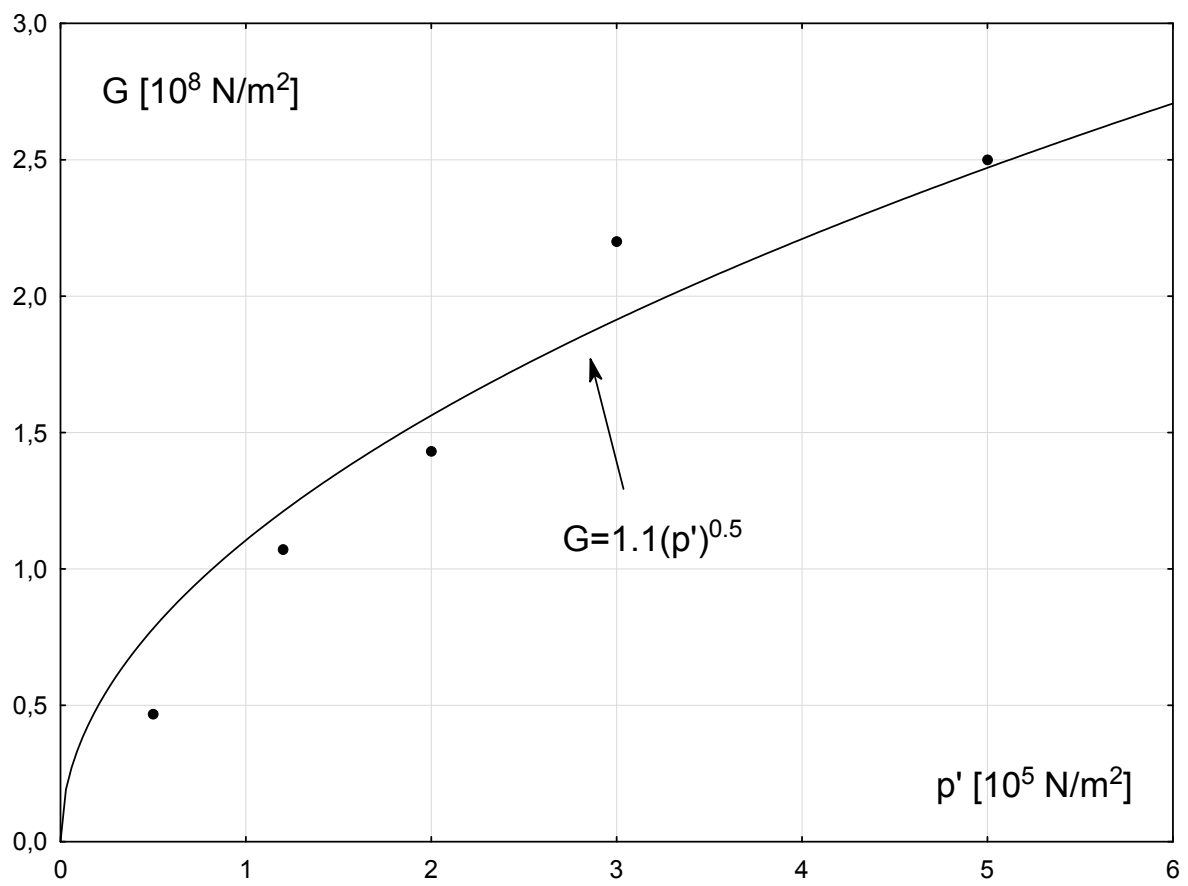

Fig. 12. Relation $G=G\left(p^{\prime}\right)$ for the Dundee sand, obtained from static triaxial tests

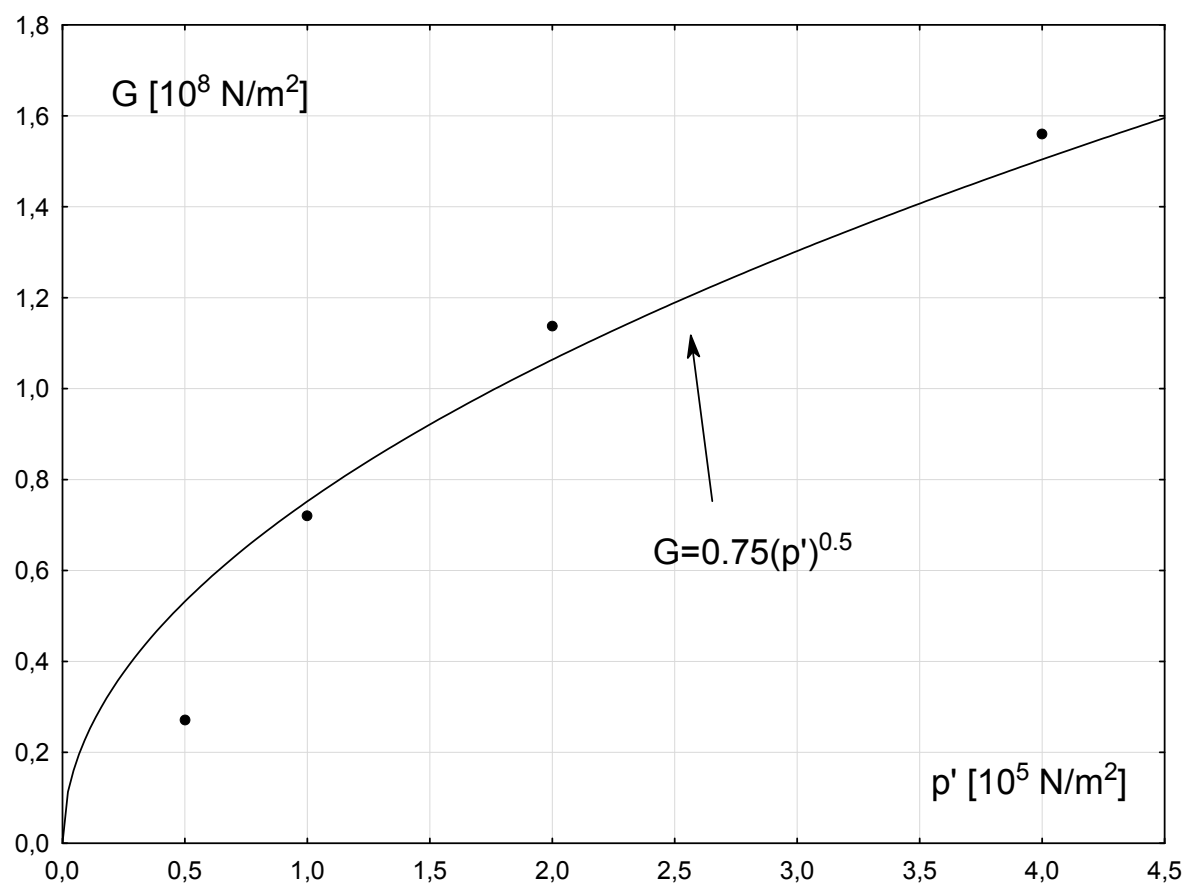

Fig. 13. Relation $G=G\left(p^{\prime}\right)$ for the Istanbul sand, obtained from static triaxial tests 


\section{Acknowledgement}

This paper has been written as part of the EU research project MERMAID. Financial support from the European Union is kindly acknowledged.

\section{References}

Ishihara K. (1996), Soil Behaviour in Earthquake Geotechnics, Oxford Science Publications, Clarendon Press, Oxford.

Ishihara K., Troncoso J., Kawase Y. and Takahashi Y. (1980) Cyclic strength characteristics of tailing materials, Soils and Foundations, 20, 4, 127-142.

Jefferies M. and Been K. (2006) Soil Liquefaction, Taylor and Francis, London/New York.

Lade P. V. and Yamamuro J. A. - Eds (1999) Physics and Mechanics of Soil Liquefaction, Balkema, Rotterdam/Brookfield.

Papathanassiou G., Mantovani A., Tarabusi G., Rapti D., Caputo R. (2015) Assessment of liquefaction potential for two liquefaction prone areas considering the May 20, 2012 Emilia (Italy) earthquake, Engineering Geology 189, 1-16.

PIANC (2001) Seismic design guidelines for port structures, Balkema, Lisse/Abingdon/Exton $(\mathrm{Pa}) /$ Tokyo.

Rahman Md. Z., Siddiqua S., Kamal A. S. M. M. (2015) Liquefaction hazard mapping by liquefaction potential index for Dhaka City, Bangladesh, Engineering Geology, 188, 137-147.

Saada A. and Bianchini G. - Eds (1989) Constitutive Equations for Granular Non-Cohesive Soils, Balkema, Rotterdam/Brookfield.

Sawicki A. (1987) An engineering model for compaction of sand under cyclic loading, Engineering Transactions, 35, 4, 677-693.

Sawicki A. and Świdziński W. (2006) A study on liquefaction susceptibility of some soils from the coast of Marmara sea, Bulletin of the Polish Academy of Sciences, Technical Sciences, 54, 4, 405-418.

Sawicki A., Mierczyński J. and Świdziński W. (2014a) Basic set of experiments for determination of mechanical properties of sand, Bulletin of the Polish Academy of Sciences, Technical Sciences, 62 , $1,1-9$.

Sawicki A., Mierczyński J., Mikos A. and Sławińska J. (2014b) Liquefaction resistance of the granular soil containing some admixtures of fines, submitted for possible publication.

Tsuchida H. (1970) Prediction and counter measure against the liquefaction in sand deposits (in Japanese), Seminar in the Port and Harbor Research Institute, Ministry of Transport. 